\title{
Timothy Grass Pollen IgG Measurement
}

National Cancer Institute

\section{Source}

National Cancer Institute. Timothy Grass Pollen Ig G Measurement. NCI Thesaurus. Code C130090.

A measurement of the Timothy grass (Phleum pretense) pollen IgG in a biological specimen. 